\title{
UCRL-TR-222940
}

LAWRENCE LIVERMORE N A T IO N A L LABORATORY
LLNL Capabilities in Underground Coal Gasification

S. Julio Friedmann, Elizabeth Burton, Ravi Upadhye

July 19, 2006 
This document was prepared as an account of work sponsored by an agency of the United States Government. Neither the United States Government nor the University of California nor any of their employees, makes any warranty, express or implied, or assumes any legal liability or responsibility for the accuracy, completeness, or usefulness of any information, apparatus, product, or process disclosed, or represents that its use would not infringe privately owned rights. Reference herein to any specific commercial product, process, or service by trade name, trademark, manufacturer, or otherwise, does not necessarily constitute or imply its endorsement, recommendation, or favoring by the United States Government or the University of California. The views and opinions of authors expressed herein do not necessarily state or reflect those of the United States Government or the University of California, and shall not be used for advertising or product endorsement purposes.

This work was performed under the auspices of the U.S. Department of Energy by University of California, Lawrence Livermore National Laboratory under Contract W-7405-Eng-48. 


\section{LLNL Capabilities in Underground Coal Gasification}

\section{Introduction}

Underground coal gasification (UCG) has received renewed interest as a potential technology for producing hydrogen at a competitive price particularly in Europe and China $^{1,2}$. The Lawrence Livermore National Laboratory (LLNL) played a leading role in this field and continues to do so. It conducted UCG field tests in the nineteen-seventies and -eighties resulting in a number of publications culminating in a UCG model published in $1989^{3}$. LLNL successfully employed the "Controlled Retraction Injection Point” (CRIP) method in some of the Rocky Mountain field tests near Hanna, Wyoming. This method, shown schematically in Fig.1, uses a horizontally-drilled lined injection well where the lining can be penetrated at different locations for injection of the $\mathrm{O}_{2} /$ steam mixture. The cavity in the coal seam therefore gets longer as the injection point is retracted as well as wider due to reaction of the coal wall with the hot gases. Rubble generated from the collapsing wall is an important mechanism studied by Britten and Thorsness ${ }^{3}$.

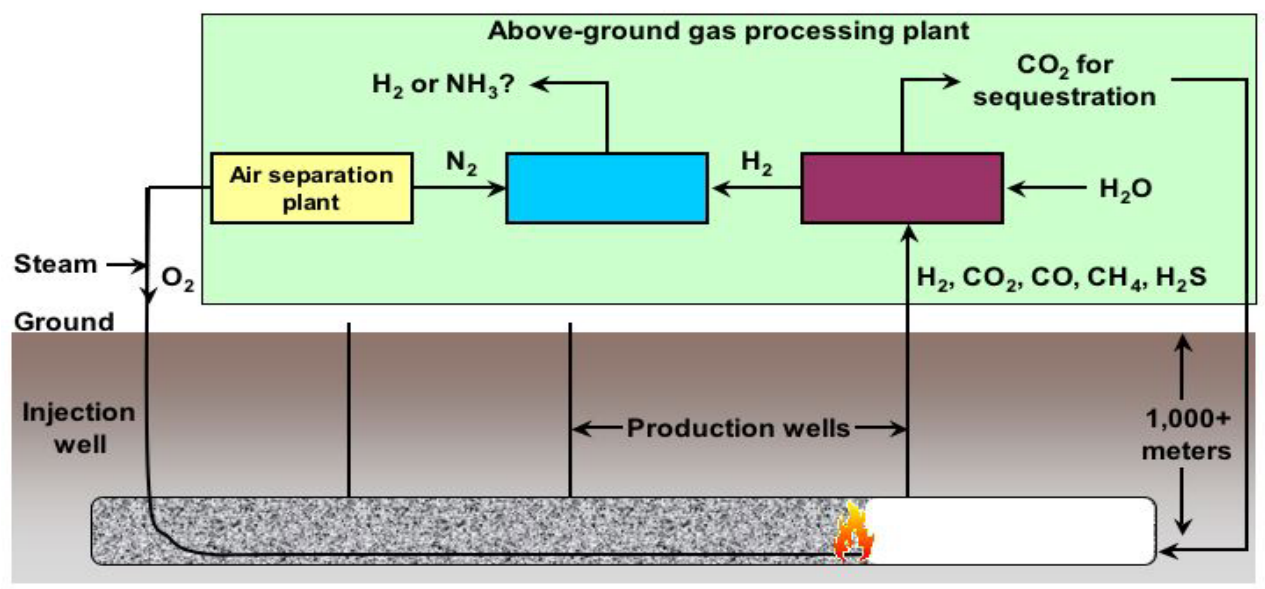

Fig.1. Schematic diagram of UCG using the CRIP method, surface processing for $\mathrm{H}_{2}$ generation, and reinjection of $\mathrm{CO}_{2}$ into gasification zone

More recently, LLNL has investigated issues associated with UCG siting ${ }^{4}$, environmental management, and $\mathrm{CO} 2$ management is combination with $\mathrm{UCG}^{5}$. We have provided recent congressional testimony ${ }^{6}$ and received funding from the US DOE to assemble a bestpractices report. Based on our past and current acitivites, we have been invited to speak at an industrial workshop this summer, are convening an industrial conference this fall, and are leading a US-Indian bilateral team on UCG. The Energy and Environment Directorate and its Earth System Science and Engineering program currently supports new research and expanded capabilities in UCG.

As a result of over three decades of work in this field, LLNL has developed significant capabilities in UCG. These are detailed below, and continue to expand through dedicated research and committed investigators.

\section{Computational Fluid Dynamic model of the UCG process, combined with Aspen modeling of surface facilities}


LLNL has developed a simplified Computational Fluid Dynamic (CFD) model of the UCG process. The model consists of an underground coal seam, approximated as a hollow tube with a given coal thickness. Steam and Oxygen are fed through an injection well, and the product syngas is harvested via a production well located at a fixed distance from the injection well. Fluid mechanically the cavity was treated as a $k, \varepsilon$ turbulent zone while the coal was a laminar zone with a solid (carbon) present to account for heat conduction. A mass source of a combination of $\mathrm{H}_{2} \mathrm{O}_{(\mathrm{l})}$ and $\mathrm{CH}_{4}$ in the coal zone simulated the influx of liquid water and the pyrolysis of coal. In fact, the coal zone in the calculation would in reality be a coke zone possessing porosity because of pre-pyrolysis of the coal. An approximately $1 \mathrm{~cm}$ thick thermal wave penetrates the coal ahead of the main combustion/ reforming reaction wave resulting in the pre-pyrolysis. Here it was assumed that $1 \mathrm{~mol}$ $\mathrm{CH}_{4}$ is formed from 5 moles of coal modeled as $\mathrm{CH}_{0.8}$. The $\mathrm{CH}_{4}$ in the model is transported by convection and diffusion toward the interface and therefore through the combustion/ reforming reaction zone. It is important that this $\mathrm{CH}_{4}$ and the reaction products produce a net mass flux at the interface hence producing a so-called "blowing” boundary layer. Oxygen must be transported against this convective flux in order to reach the interface. Gaseous water in the case of a zero liquid water influx would also have to overcome this transport barrier to reach the interface. However, most cases studied here included a liquid water influx providing gaseous water from the coal-side to the interface. The importance of the transport of reactants through the blowing boundary layer required a realistic gas velocity such as $10 \mathrm{~m} / \mathrm{s}$ to be used. This in turn meant that the 10 meter long channel was not sufficiently long to deplete the injected $\mathrm{O}_{2}$. Gasification yields therefore are expressed per mol of consumed $\mathrm{O}_{2}$ implying that the same yield would be obtained in a long channel that depletes the oxygen. This scale-up principle is an approximation that needs refinement in future work.

Table 1. Typical UCG gas compositions adjusted to $33 \mathrm{~mol} \%$ water content.

\begin{tabular}{|l|l|l|}
\hline Component & UCG Model & Field Measurement \\
\hline $\mathrm{H}_{2}$ & 27.2 & 27.3 \\
\hline $\mathrm{CO}$ & 13.0 & 6.4 \\
\hline $\mathrm{CO}_{2}$ & 19.4 & 27.2 \\
\hline $\mathrm{CH}_{4}$ & 7.4 & 6.4 \\
\hline $\mathrm{H}_{2} \mathrm{O}$ & 33.0 & 33.0 \\
\hline
\end{tabular}

(1) Average for day 40-50 from CRIP reactors at RM I3

A comparison of gas product composition between model and experiment is shown in Table 1 (water added to make both water contents equal to $33 \%$ ). $\mathrm{H}_{2}$ and $\mathrm{CH}_{4}$ agree well, but the field experiment shows much more $\mathrm{CO}_{2}$ (and less $\mathrm{CO}$ ) than the model. The high $\mathrm{CO} / \mathrm{CO}_{2}$ ratio in model reflects a high-temperature water-gas equilibrium (approximately $1400 \mathrm{~K})$ implying "frozen" kinetics, i.e. the water-gas shift kinetics are too slow at lower temperatures to reduce the ratio down to values closer to the experimental value. In reality with a longer channel and therefore longer gas residence time (residence time is only of the order 1 second here) the $\mathrm{CO} / \mathrm{CO}_{2}$ ratio should decrease. However, this is not considered too important because the surface plant will reduce this ratio very effectively in the catalytic membrane reactor. 
We have also developed Aspen models of the surface facilities for gas cleanup, H2 to CO balancing via the water-gas shift reaction, and subsequent utilization of the syngas for the production of power and chemicals, such as ammonia, methanol, or transportation fuels.

\section{Combustion and Hydrocarbon Kinetics Modeling}

Over the last 20 years, the LLNL combustion chemistry group has developed detailed chemical kinetic mechanisms for hydrocarbons. These mechanisms are used worldwide by industrial and university researchers for modeling the chemistry of fuels in internal combustion engines and the emission of air toxic species from refinery burners. The hydrocarbons that we can model include alkanes up to iso-octane and n-heptane, aromatics including benzene and toluene, and cyclo-alkanes including methyl-cyclohexane.

Additionally, our detailed chemical kinetic models can treat the chemistry of oxygenated species such as formaldehyde, other aldehydes, plus selected alcohols, ethers, and methyl esters. We can also model the detailed chemistry of the formation of air toxic species such as benzo-a- pyrene, aldehydes, butadiene, and other species on the 1990 Clean Air Act list. The models include nitrogen chemistry necessary for the prediction of the emissions of oxides of nitrogen. Our models have sufficient chemistry to represent the chemistry of all the key chemical classes of n-alkanes, iso-alkanes, cyclo-alkanes, alkenes, aromatics, PAHs, and oxygenated hydrocarbons. This capability can be used to represent the chemistry of volatile organic hydrocarbons coming off from the in situ burning of underground coal. The chemistry of the evolution of these volatile organic hydrocarbons can be followed as they react with air and steam to form carbon monoxide and hydrogen or possibly react to form undesirable products, such as air toxic species and $\mathrm{NO}_{\mathrm{x}}$.

\section{Environmental Issues In Underground Coal Gasification}

LLNL can assist UCG operations at both the project planning/site selection stage and during operation by providing the necessary tools and expertise to perform site assessments and to design and implement groundwater monitoring and treatment systems.

\section{Coupled Processes Affecting UCG Contaminant Fate \& Transport}

- Thermally-driven upward flow of groundwater resulting from in situ burning of coal;

- Buoyancy effects from fluid density differences reflecting gradients in dissolved solids content and temperature of groundwater;

- Partitioning of organic compounds and dissolved metals onto mineral surfaces during solute transport;

- Bioattenuation of organic compounds derived from coals that migrate into potable water aquifers.
The environmental threat posed to groundwater resources as a result of underground coal gasification (UCG) is comprised of three principal elements: the generation of contaminants within the burn chamber, enhanced vertical hydraulic conductivity of the rock matrix above the burn chamber as a result of collapse and fracturing, and buoyancy-driven upward flow of groundwater in the vicinity of the burn chamber toward potable water resources at shallower depths.

The complexity of UCG systems requires use of hydrological, geochemical and geomechanical models that presently are unavailable commercially or in most private environmental consulting firms. LLNL has been involved in UCG research and development since 1970's as well as in much environmental research tracking the fate and transport of a variety of hazardous contaminants 
from UCG burns and under similar types of unusual conditions underground (e.g., underground nuclear testing). From this experience, LLNL has devised a suite of modeling tools that are appropriate to simulating the environmental consequences of UCG operations, including risk-based decision-making (RBDM) during UCG design stages or planning and design of environmental mitigation or remediation strategies for existing operations.

Figure 2. RBDM flow diagram for UCG operations.

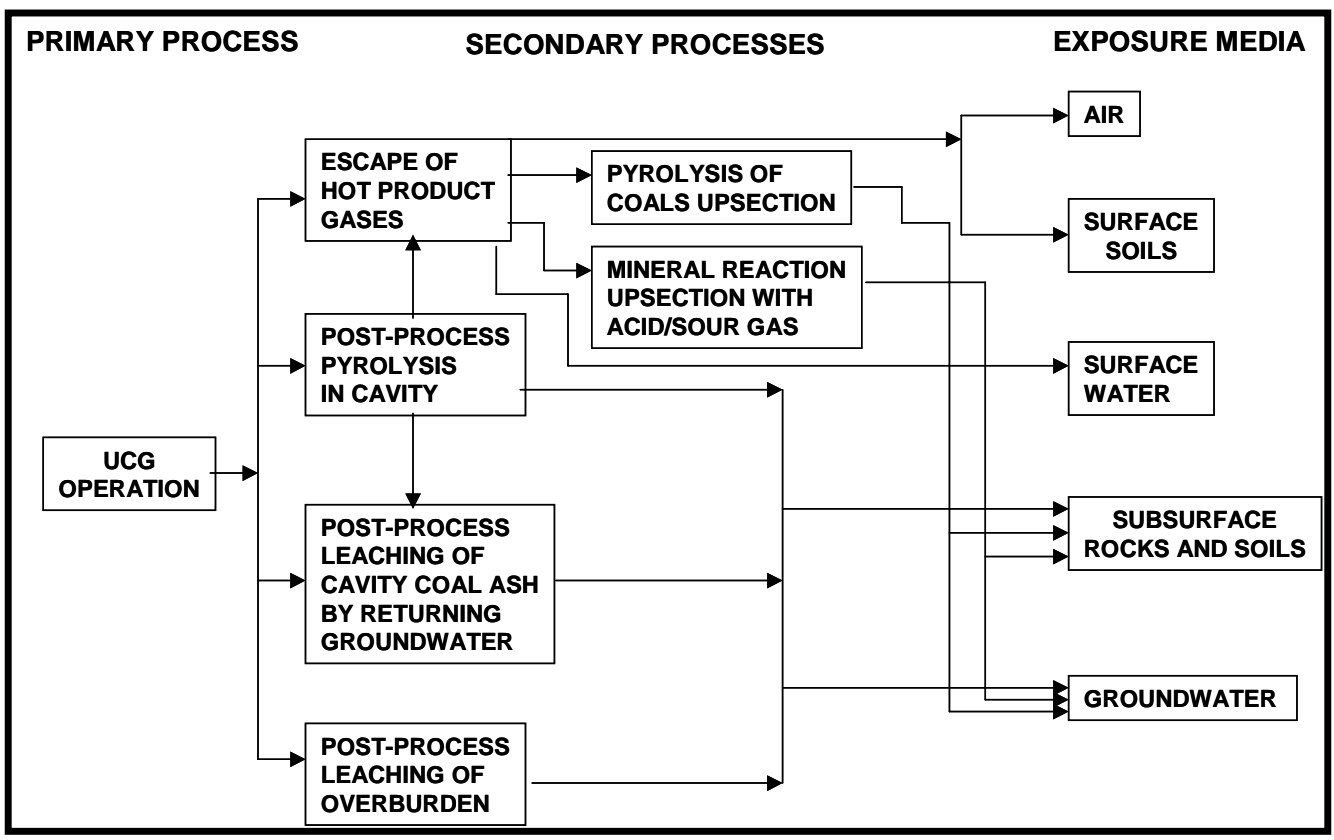

This makes LLNL uniquely positioned with the expertise to assess the feasibility of managing UCG environmental risk and to perform any subsequent data acquisition or customization to modify transport models to improve risk management. The team of scientists at LLNL has expertise in hydrogeology, reactive transport, rock mechanics and physics, organic geochemistry, and inorganic/mineral geochemistry. The current team also has available a unique resource of LLNL scientists who were involved in previous UCG research pilots of the 1970s.

LLNL has an array of laboratory facilities capable of simulating the conditions of UCG. Geochemical facilities include high-temperature high-pressure reactors to study the mobility of organic compounds under the subsurface conditions that typify UCG sites, equipment to measure contaminant solubilities in water and supercritical $\mathrm{CO}_{2}$ and to track transport of contaminants through rock pores and fractures. LLNL scientists also have developed the experimental protocols and procedures that allow precise and accurate measurements of these types of organic compounds in $\mathrm{CO}_{2}$ or aqueous solvents.

\begin{tabular}{c}
\hline LLNL Areas of UCG \\
Environmental Expertise \\
\hline Geochemistry \\
Laboratory testing \\
Modeling \\
Analytical support \\
Geomechanics \\
Laboratory testing \\
Modeling \\
Geological Assessments \\
Structural \\
Stratigraphic \\
Hydrologic \\
Risk Assessment \\
Environmental \\
Health \\
Safety \\
Environmental \\
Remediation \\
Bioattenuation
\end{tabular}



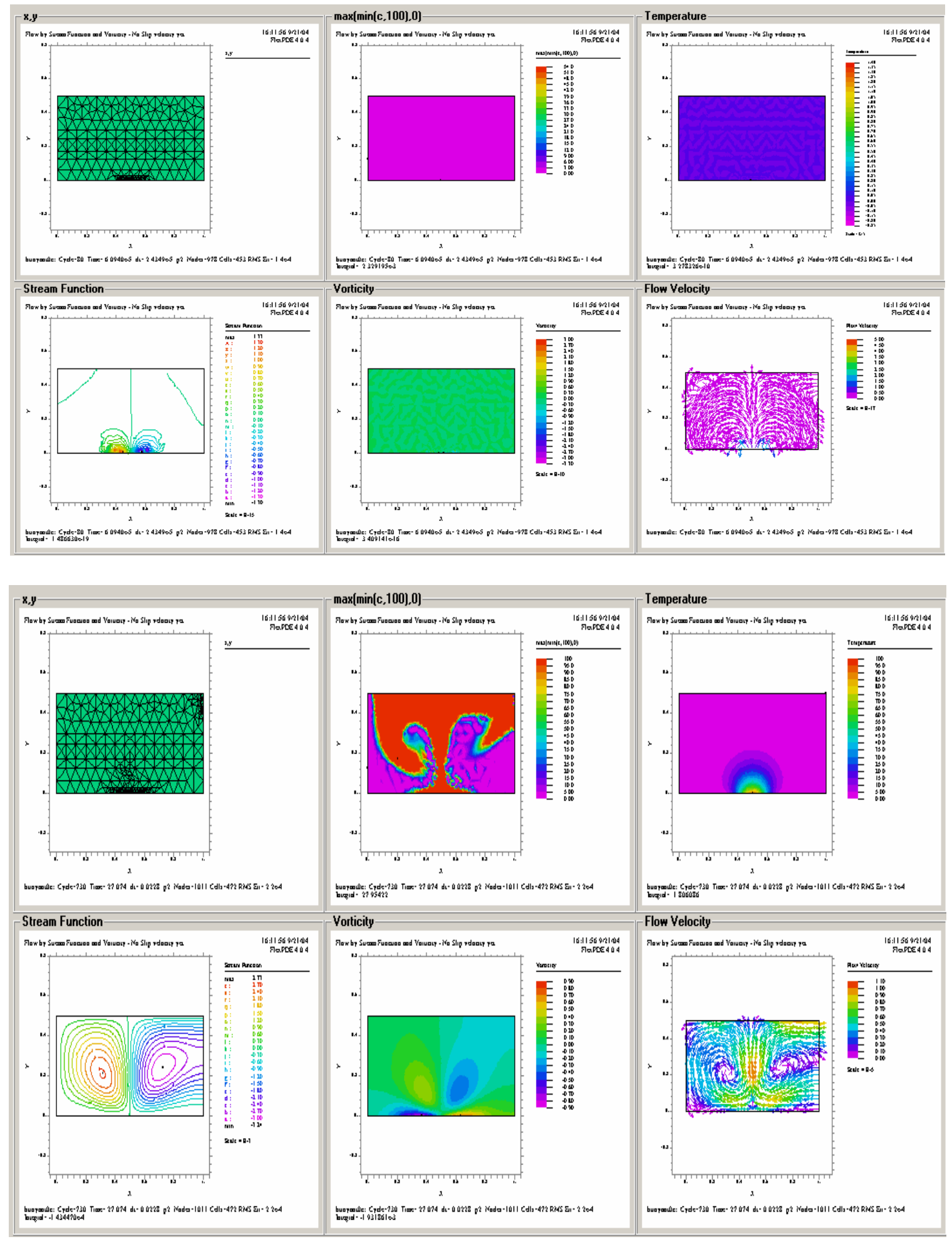

Figure 3. Example of flow and thermo-convection in a vertical cross section over time. Each set of 6 figures corresponds to: the mesh, the concentration of a contaminant, the temperature field, the resulting stream function, vorticity, and the flow field (velocity). The upper set represents the initial conditions where the bottom line of the domain represents the roof of the seam. In the middle of roof, it is assumed that the burning chamber has "collapsed" resulting in a source of heat and contaminants. The lower set shows the development of convection cells (stream function and velocity) that result in an upward movement of the leaking contaminant (mushroom-like cloud in red). 
LLNL expertise in hydrogeology, contaminant transport and reactive transport modeling can address a variety of environmental issues in applied remediation scenarios and in conceptual studies. These models collectively include consideration of reactive transport, bioattenuation, and geomechanical processes on contaminant migration, and may be applied to aqueous and/or supercritical $\mathrm{CO}_{2}$ systems.

\section{Carbon Management and Underground Coal Gasification}

Since 1998, LLNL has played a leadership role in research into $\mathrm{CO}_{2}$ management, specifically $\mathrm{CO}_{2}$ capture and storage (CCS, or geosequestration). This has included funding in the $\mathrm{CO}_{2}$ Capture Project (CCP), participation in three DOE Regional Partnerships and GEO-SEQ programs, including the Frio Brine Pilot. We have received funding and continue to receive funding in aspects of $\mathrm{CO}_{2}$ capture engineering and $\mathrm{CO}_{2}$ storage simulation, risk assessment, and monitoring.

Because UCG syngas reaches the surface at elevated pressure and high temperature, decarbonization may proceed at reduced cost. In some cases (e.g., water-shift separation or partial decarbonization through PSA) at extremely low cost ${ }^{5}$. LLNL has begun to investigate both traditional and novel means of UCG decarbonization as part of an integrated energy and environmental strategy.

Given the advantages UCG provides to carbon capture, one can think about opportunities for storage as well. In a conventional context, $\mathrm{CO}_{2}$ may be stored in geological targets such as saline formations, depleted oil and gas fields, and unmineable coal seams (typically at a depth $>800 \mathrm{~m}$ ). LLNL researchers are beginning to investigate the specific siting and integration aspects of UCG+CCS, with focus on the integrated systems engineering of the UCG process, surface treatment, and continuous injection stream. This work exists mostly as part of our current $\mathrm{CO}_{2}$ storage program, and focuses on three components:

o Advanced simulation: Reactive transport simulation provides the main platform for investigation (above), integrating hydrological, geochemical, and geomechanical processes. These models are underlain by integrated laboratory experiments, including co-contaminant effects (e.g., $\mathrm{H}_{2} \mathrm{~S}, \mathrm{SO}_{\mathrm{x}}$, and $\mathrm{NO}_{\mathrm{x}}$ injection)

o Integration of monitoring data streams: In addition to providing novel monitoring methods (below), LLNL places special emphasis in integration and joint inversion of geophysical, geochemical, and operational data streams to provide robust, quantitative information for decision making.

- Quantification of risk: LLNL has developed proprietary tools for carbon management, including source term definition, prediction, and modeling, GISbased risk screening, and site characterization capabilities.

In addition to conventional storage, $\mathrm{CO}_{2}$ may be stored in the in-situ gasification zone ${ }^{5}$. This has substantial advantages, including the creation of porosity and permeability, local engineering control, use of pre-existing wells, and exploitation of properties of coal that might lead to auto-closure (e.g., swelling and $\mathrm{CO}_{2}$ adsorption). However, the gasification process also dramatically alters the coal seam and hydrological system in ways that are difficult to estimate or predict (Figure 4). As such, $\mathrm{CO}_{2}$ injection into the gasification zone would carry substantial risks not thoroughly understood or studied in the field. LLNL has begun the process of delineating the most critical concerns and a research program aimed at investigating the key processes and mechanisms of $\mathrm{CO}_{2}$ storage risk. These include: 
o T-P-D constraints for operation: The cavity temperature at a given pressure must be sufficiently low to avoid flashing or boiling of $\mathrm{CO}_{2}$ at injection pressures. Similarly, the injection pressure must be sufficient to remain supercritical and ideally to prevent flashing.

- Geomechanical response: The injection pressure must exceed hydrostatic pressures to displace cavity water. This will prompt a number of geomechanical responses, such as fracture dilation, crustal uplift, and potentially inducing fracture.

- Ground-water displacement risk: Cavity injection above hydrostatic pressures will displace UCG zone brines into the coal seam and adjoining formation. This may flush VOCs or metals from the cavity into saline aquifers or coals.

- Geochemical response: $\mathrm{CO}_{2}$ injection will form carbonic acid in the cavity, which may react quickly with the coal, rock, ash, or slag in the cavity. This could leach metals, sulfur, and other harmful species into the UCG zone water, further altering the local chemistry and increasing risk.

- $\quad \mathrm{CO}_{2}$ fate: Free-phase $\mathrm{CO}_{2}$ would remain supercritical and buoyant, applying upward pressure on the cavity. The geomechanical, fault migration, and well-leakage risks may be greater than conventional storage due to the thermal stresses and shocks of heating and quenching.

Currently, LLNL is supporting this research internally. We have requested funds from the US DOE to continue this work, and have signed a MOU with ErgoExergy Inc. to look for appropriate opportunities to conduct lab- and fieldbased investigations on this subject.

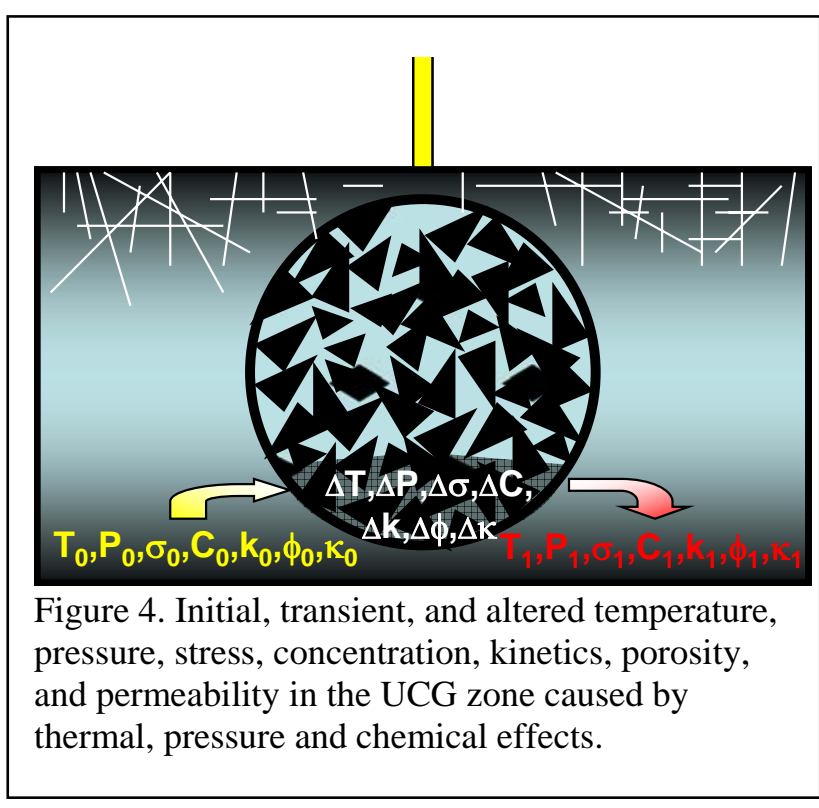

\section{Monitoring and Petrophysics}

To date, monitoring of UCG projects and burns has been quite limited. No geophysical surveys have been deployed during UCG projects. Although the Chinchilla project extensively sampled groundwater for chemistry and pressure, no other geochemical or operational monitoring occurred. As such, substantial uncertainty exists in subsurface process, engineering, environmental concerns, risk, and even footprint of operation.

LLNL is committed to helping to close these critical gaps in UCG knowledge. First, we have developed and utilized in the field many geophysical and geochemical monitoring technologies. These include electrical resistance tomography (ERT); electromagnetic induction tomography (EMIT); use of smart casing; passive seismic monitoring (e.g., microseismic); and crustal deformation tools such as tilt-meter, InSAR, and GPS. This work naturally dovetails into the integrated inversion methodologies. Second, we have developed forward geophysical solvers. These may be used to understand and predict the acoustic, thermal, electrical, deformational, and gravitational transients caused by UCG. 
This information can serve as the basis for developing a fit-for-purpose monitoring suite for UCG.

LLNL also has laboratory facilities for measurements and experiments in rock physics and geomechanics, including measuring the effects of UCG burn-induced changes in stress fields on rock mechanical and physical properties and performing experiments simulating the effects of UCG on rock-fluid systems. These facilities are second to none, and are ideal for both representing extreme conditions and collecting petrophysical measurements through multiple methodologies.

\section{Summary}

LLNL has the tools and expertise to provide the technical framework to apply a proactive RBDM approach to UCG. LLNL can combine the best commercially available simulation codes with its proprietary hydrologic, geomechanical and geochemical models to predict the fate and transport of UCG-generated contaminants along potential exposure pathways.

\section{References}

1. Collot, A.-G. "Prospects for Hydrogen from Coal” IEA Coal Research, The Clean Coal Centre, London, U.K., 2003.

2. Creedy, D.P., Garner, K., Oakley, J.E., Abbott, D., Edwards, J.S., Ren, T.X., Liang, J., Liu, S., Chai “Clean Energy from Underground Coal gasification in China” Report No. COAL R250, DTI/Pub URN 03/1611, DTI Cleaner Fossil Fuels Programme, Oxfordshire, U.K., 2004.

3. Britten, J.A., Thorsness, C.B. “A Model for Cavity Growth and Resource Recovery during Underground Coal Gsification” In-Situ 13, 1-53 (1989).

4. Friedmann, S.J. 2004, Rapid Qualitative Risk Assessment for Contaminant Leakage From Coal Seams During Underground Coal Gasification and $\mathrm{CO}_{2}$ Injection, Lawrence Livermore National Lab, Report UCRL-TR-205194

5. Blinderman, M.S., and Friedmann, S.J., 2006, Underground Coal Gasification with Carbon Capture and Storage: A Pathway to a Low-Cost, Low-Carbon Gas for Power Generation and Chemical Syntheses, NETL $5^{\text {th }}$ Annual Conference on Carbon Sequestration, Alexandria, VA, ExchangeMonitor Publications

6. Friedmann, S.J, 2005, Underground Coal Gasification in the USA and Abroad, Congressional hearing on climate change, November 14 in the Senate Foreign Relations Committee 


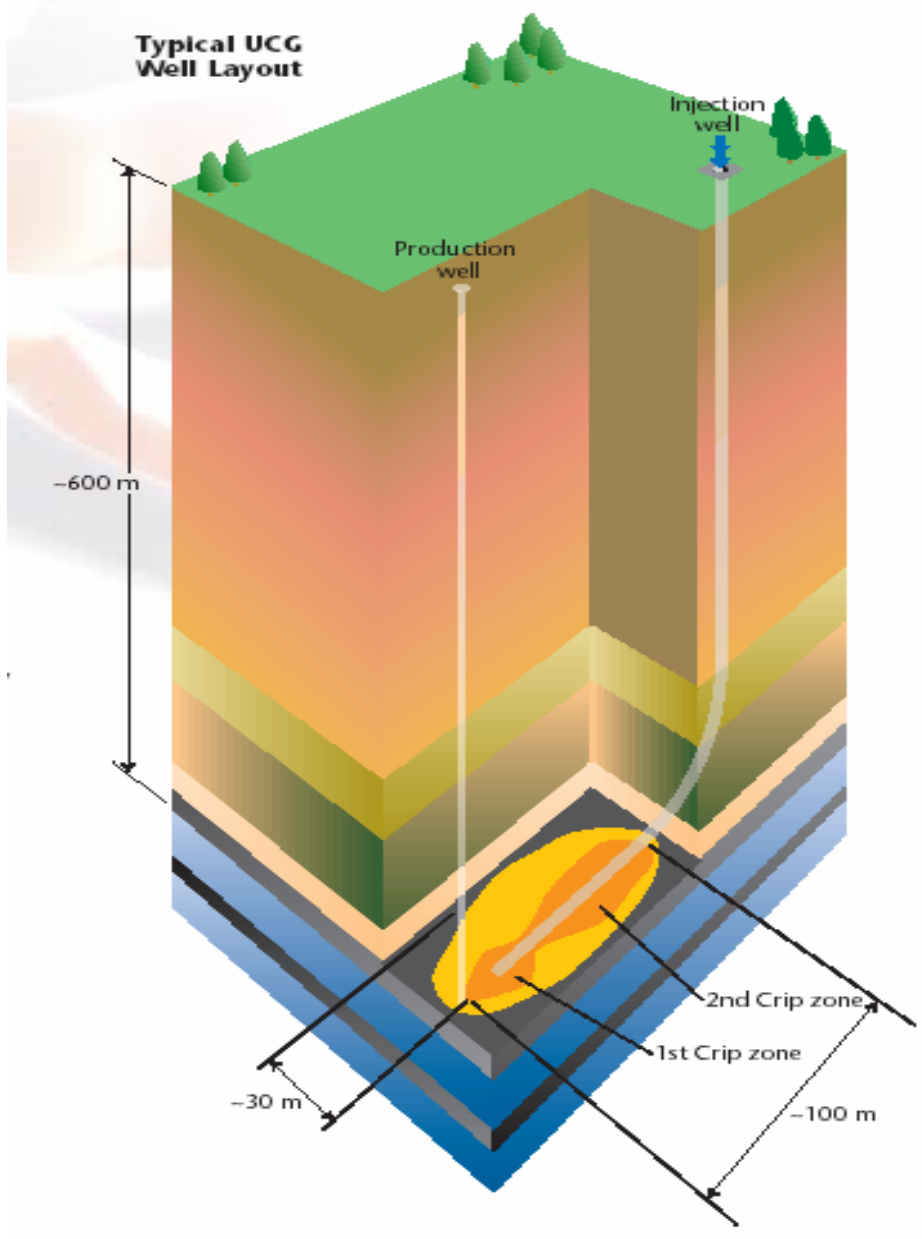

